\title{
Pulmonary veno-occlusive disease presenting with recurrent pulmonary oedema and the use of nitric oxide to predict response to sildenafil
}

\author{
B C Creagh-Brown, ${ }^{1}$ A G Nicholson, ${ }^{2}$ R Showkathali, ${ }^{3}$ J S R Gibbs, ${ }^{3}$ L S G E Howard ${ }^{3}$
}

${ }^{1}$ Royal Brompton Hospital, London, UK; ${ }^{2}$ Royal Brompton Hospital, London, UK; ${ }^{3}$ National Pulmonary Hypertension Service, Department of Cardiac Sciences, The Hammersmith Hospitals NHS Trust, London, UK

\section{Correspondence to:}

Dr B C Creagh-Brown, St George's Hospital, Blackshaw Road, Tooting, London SW17 00T, UK; drbencb@gmail.com

Received 17 August 2007 Accepted 22 January 2008

\begin{abstract}
Pulmonary veno-occlusive disease (PVOD) is a disorder which causes progressive pulmonary hypertension, usually presenting with worsening dyspnoea and right heart failure. Pulmonary oedema induced by pulmonary vasodilator therapy to reduce pulmonary arterial pressure has been well described in PVOD, but here we describe a case of PVOD presenting with recurrent episodes of acute non-cardiogenic pulmonary oedema, in the absence of significant pulmonary hypertension. Concern over the risk of precipitating pulmonary oedema led us to use inhaled nitric oxide to predict the safety and efficacy of sildenafil.
\end{abstract}

Pulmonary veno-occlusive disease (PVOD) usually presents with worsening dyspnoea and right heart failure as a result of pulmonary arterial hypertension (PAH). Here we describe a case of PVOD presenting with recurrent episodes of acute noncardiogenic pulmonary oedema with only a borderline increase in pulmonary artery pressure, confounding the diagnosis until surgical lung biopsy was performed. In view of the risk of precipitating pulmonary oedema with vasodilator therapy, we also report on the use of inhaled nitric oxide to predict the safety and efficacy of sildenafil.

\section{CASE REPORT}

A previously healthy 21-year-old Afro-Caribbean male presented with a $2 \mathrm{~h}$ history of breathlessness. There was no associated chest pain, cough, wheeze or fever. He was apyrexial and had a saturation of $90 \%$ on high flow oxygen. He was tachycardic in sinus rhythm with a blood pressure of 110/70 $\mathrm{mm} \mathrm{Hg}$. He had widespread inspiratory crackles. His chest radiograph is shown in fig 1A. Routine blood tests revealed neutrophilia with a C reactive protein level of $4 \mathrm{mg} / \mathrm{l}$. He started on continuous positive airway pressure (CPAP) and was treated for pneumonia with intravenous cefuroxime and clarithromycin. Pending results of an HIV test (subsequently negative), he received septrin and prednisolone for 2 days. Microbiological investigations for pneumonia were negative. Rheumatoid factor, sickle solubility test, serum ACE and autoantibodies were also negative.

He improved rapidly over 2 days, with complete resolution of radiographic changes, but remained persistently hypoxaemic with exertional breathlessness and desaturation (from 93\% to $76 \%$ ). A CT excluded a pulmonary embolus and indirect evidence of PAH, such as dilated pulmonary arteries or right-sided cardiac chambers. There was no septal thickening, but extensive mediastinal and hilar lymphadenopathy and peripheral lung attenuation (fig 1B). Lung function showed normal lung volumes with severely impaired gas transfer (carbon monoxide transfer factor $5.09 \mathrm{mmol} / \mathrm{min} /$ $\mathrm{kPa}(43 \%), \mathrm{KCO} 1.0 \mathrm{mmol} / \mathrm{min} / \mathrm{kPa} / \mathrm{l}(59 \%))$. Given these findings and because of the rapid response presumed secondary to steroids, he was restarted on oral prednisolone $40 \mathrm{mg}$, with a presumptive diagnosis of sarcoidosis.

Following discharge he was readmitted twice in quick succession with similar clinical and radiographic findings, responding rapidly to CPAP. On both occasions he had also reported streaky haemoptysis and frothy sputum. Transbronchial biopsy was inconclusive. Thoracoscopic lung biopsy showed patchy capillary congestion within the alveolar parenchyma and marked intimal changes in veins and venules, the features characteristic of PVOD (fig 2). He was transferred in to the National Pulmonary Hypertension Service, where echocardiography showed a mildly dilated right ventricle (RV) with moderately impaired systolic function. Estimated RV systolic pressure was $41 \mathrm{~mm} \mathrm{Hg}$. Left-sided cardiac chambers were normal. Subsequent cardiac MRI showed a structurally normal heart. Cardiac catheterisation demonstrated borderline elevation of mean pulmonary artery pressure $(26 \mathrm{~mm} \mathrm{Hg})$, with normal mean wedge pressure $(7 \mathrm{~mm} \mathrm{Hg})$ and left ventricular end diastolic pressure $(8 \mathrm{~mm} \mathrm{Hg})$, cardiac index of $4.51 / \mathrm{min} / \mathrm{m}^{2}$ and pulmonary vascular resistance of $160 \mathrm{dyn} \times \mathrm{s} / \mathrm{cm}^{5}$. He was anticoagulated, treated with low dose diuretic and referred for lung transplantation, which he declined.

He was stable for 6 months, and only on routine follow-up admitted worsening WHO functional class IV symptoms over the past month. He was severely hypoxaemic $\left(\mathrm{PaO}_{2} 5.4 \mathrm{kPa}\right.$ on $40 \%$ oxygen): a chest radiograph and high resolution $\mathrm{CT}$ showed little change. An echocardiogram showed severely impaired RV systolic function with an estimated RV systolic pressure of $82 \mathrm{~mm} \mathrm{Hg}$ and normal left ventricular function. He was given a trial of inhaled nitric oxide (NO) at $40 \mathrm{ppm}$ in intensive care: his saturations increased from $93 \%$ on $40 \%$ oxygen to $99 \%$ on air. He was therefore started on oral sildenafil $50 \mathrm{mg}$ three times daily and improved to WHO functional class III with saturations of $96 \%$ on $35 \%$ oxygen. Three months later he deteriorated further (again with no evidence of pulmonary oedema). Sildenafil was up-titrated to $100 \mathrm{mg}$ three times daily and intravenous epoprostenol added. At a dose of 

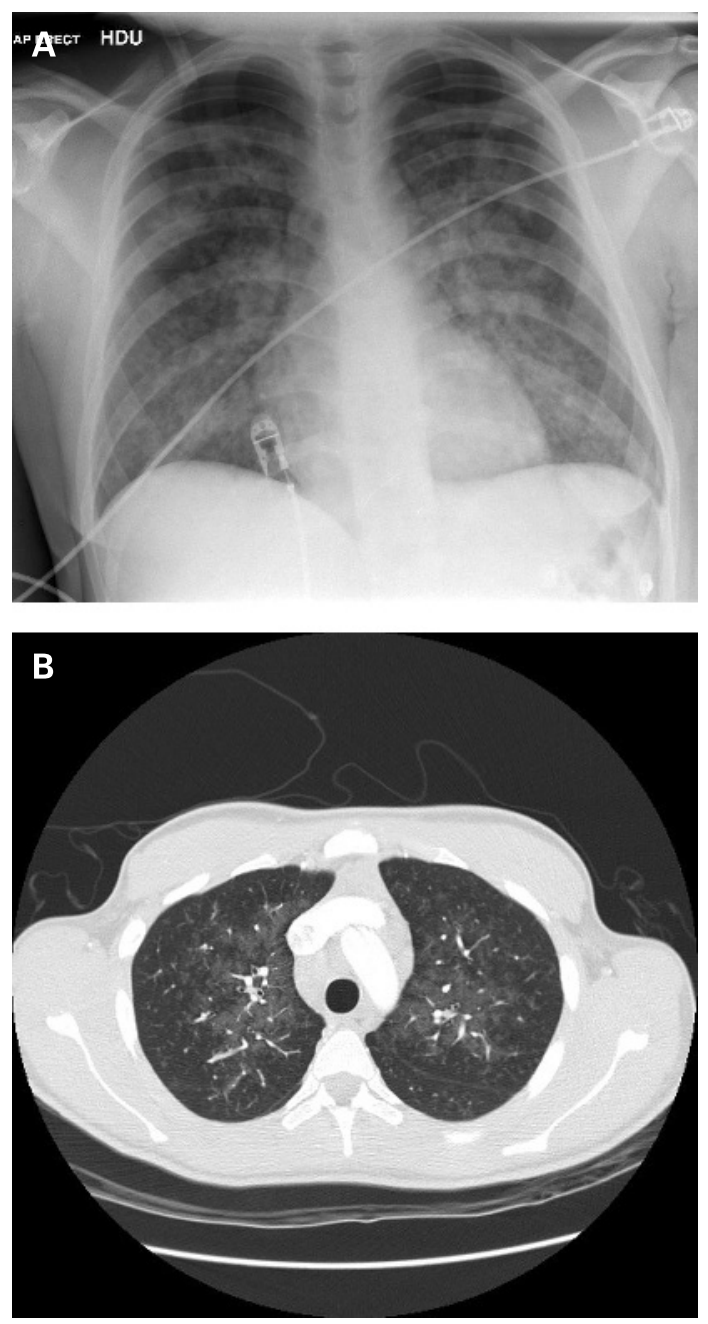

Figure 1 (A) Chest radiograph of the patient. (B) CT scan of the chest.

$20 \mathrm{ng} / \mathrm{kg} / \mathrm{min}$ he developed radiological signs of pulmonary oedema, which resolved when reduced to $18 \mathrm{ng} / \mathrm{kg} / \mathrm{min}$. He remained in severe right heart failure and was discharged home with palliative care, where he died a week later.

\section{DISCUSSION}

PVOD is a rare and incompletely understood cause of PAH with a grave prognosis. Lung transplantation is the only curative option, without which mortality is $72 \%$ at 1 year. ${ }^{1}$ Presentation is usually similar to $\mathrm{PAH}$ with progressive dyspnoea and pulmonary hypertension, but may be acute, even presenting with sudden death. ${ }^{2}$ The characteristic radiographic appearances are interlobular septal thickening, ground glass shadowing and mediastinal lymphadenopathy.

The cause of PVOD remains unclear, although associations with multiple conditions have been reported. ${ }^{1}$ The characteristic progressive and patchy narrowing and occlusion of the small postcapillary pulmonary veins causes heterogeneous areas of increased pulmonary capillary pressure, ultimately leading to pulmonary hypertension and oedema. This is in contrast with another cause of non-cardiogenic pulmonary oedema, high altitude pulmonary oedema, which induces pulmonary oedema and hypertension through exaggerated heterogeneous

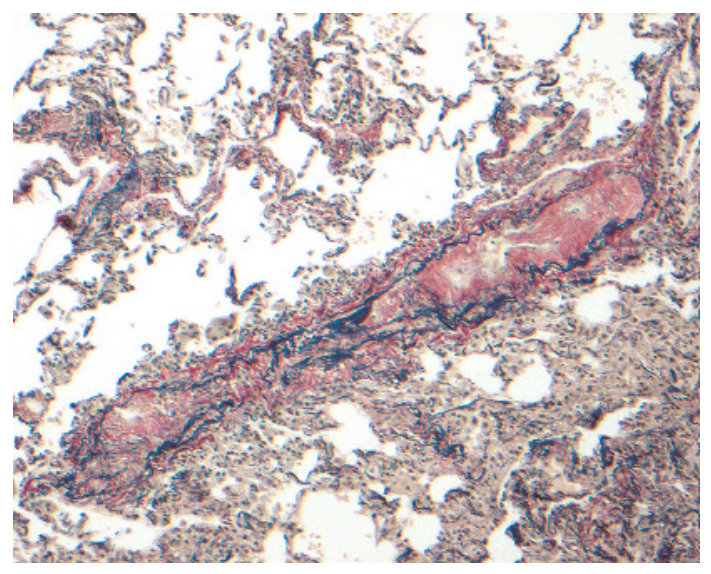

Figure 2 Thoracoscopic lung biopsy, showing patchy capillary congestion within the alveolar parenchyma and marked intimal changes in veins and venules.

pulmonary arterial vasoconstriction ${ }^{3}$ (in response to hypoxia). The unusual feature of our case was recurrent acute pulmonary oedema and the absence of significant pulmonary hypertension, although catheterisation was performed when the patient was stable. Interestingly, he later developed pulmonary hypertension, but without the classical radiographic features of PVOD.

Treatment of PVOD with pulmonary vasodilators, such as prostacyclin, is controversial as it may precipitate life threatening pulmonary oedema due to the presence of venous obstruction. ${ }^{4}$ There is a suggestion that sildenafil, which augments the NO signalling pathway by inhibiting phosphodiesterase dependent breakdown of cGMP, may have a better safety profile due to potential venodilator properties. ${ }^{5}$ We chose therefore to use $\mathrm{NO}$ to predict the short term response to sildenafil, because of its short half life. Despite initial improvement, he developed progressive pulmonary hypertension, and cautious introduction of epoprostenol unfortunately produced pulmonary oedema at a moderate dose.

This case documents that PVOD may present with recurrent acute episodes of pulmonary oedema, even in the absence of pulmonary hypertension when stable. Where there is concern over the precipitation of pulmonary oedema with vasodilator therapy used to treat pulmonary hypertension, inhaled NO may be useful to predict the response to sildenafil

Acknowledgements: The authors thank Dr Paula Johnson, Dr A Mahar and Dr James Jackson.

Competing interests: None.

Patient consent: Obtained from the patient's next of kin.

\section{REFERENCES}

1. Holcomb BW Jr, Loyd JE, Ely EW, et al. Pulmonary veno-occlusive disease: a case series and new observations. Chest 2000;118:1671-9.

2. Lantuejoul S, Sheppard MN, Corrin B, et al. Pulmonary veno-occlusive disease and pulmonary capillary hemangiomatosis: a clinicopathologic study of 35 cases. Am J Surg Pathol 2006;30:850-7.

3. Hopkins SR, Levin DL. Heterogeneous pulmonary blood flow in response to hypoxia: a risk factor for high altitude pulmonary edema? Respir Physiol Neurobiol 2006:151:217-28.

4. Palmer SM, Robinson LJ, Wang A, et al. Massive pulmonary edema and death after prostacyclin infusion in a patient with pulmonary veno-occlusive disease. Chest 1998:113:237-40.

5. Barreto AC, Franchi SM, Castro CR, et al. One-year follow-up of the effects of sildenafil on pulmonary arterial hypertension and veno-occlusive disease. Braz $\mathrm{J}$ Med Biol Res 2005;38:185-95. 
Corrections

doi:10.1136/thx.2008.102947corr1

O'Driscoll B R, Howard L S, Davison A G on behalf of the British Thoracic Society. BTS guideline for emergency oxygen use in adult patients. Thorax 2008; 63(Suppl 6):vi1-vi68.

The Guideline Development Group regret that no advice was offered for the management of status epilepticus. As this is a life-threatening condition where a patient may suffer from cerebral hypoxia (and oximetry may not be possible), patients with status epilepticus should be treated in accordance with table 1 (reservoir mask until clinically stabilised). This advice also applies to other rare conditions that may cause life-threatening hypoxaemia that are not listed specifically in table 1.

Roberts JA. Benchmarking chronic obstructive pulmonary disease across an inner city primary care trust: one year on. Thorax 2008;63(Suppl vii):A8 (abstract S12).

The correct authors for this abstract are as follows: Roberts JA, Bakerly ND.

Roberts JA. Should chronic obstructive pulmonary disease service delivery in an inner city primary care trust be targeted at general practice or practice-based commissioning cluster level? Thorax 2008;63(Suppl vii):A8 (abstract S13).

The correct authors for this abstract are as follows: Roberts JA, Bakerly ND.

Tsartsali L, Fleming L, Regamey N, et al. Relationship between non-invasive inflammatory markers and the current level of clinical control in childhood asthma. Thorax 2008;63(Suppl vii):A33 (abstract S70).

This abstract has been withdrawn.

Baird S, Ashish A, O'Connor J, et al. Respiratory assessment centre: does it increase the number of patients taken home with the early supported discharge team? Thorax 2008;63(Suppl vii):A67 (abstract S154).

It has come to the attention of the Scientific Committee that this abstract was not seen by all the authors prior to submission and is therefore withdrawn.

doi:10.1136/thx.2007.088831 corr1

Creagh-Brown B C, Nicholson A G, Showkathali R, et al. Pulmonary veno-occlusive disease presenting with recurrent pulmonary oedema and the use of nitric oxide to predict response to sildenafil Thorax 2008;63:933-4.

The address for correspondence should be: Dr B C Creagh-Brown, Adult Intensive Care Unit, Royal Brompton Hospital, London SW3 6NP, UK; drbencb@gmail.com. 